\title{
Study for the Design of a Protocol to Assess the Impact of Stress in the Quality of Life of Workers
}

\author{
Patricia Concheiro-Moscoso ${ }^{1,2}{ }^{\mathbb{D}}$, Betania Groba ${ }^{1,2, *(\mathbb{D})}$, Francisco José Martínez-Martínez ${ }^{1}$,

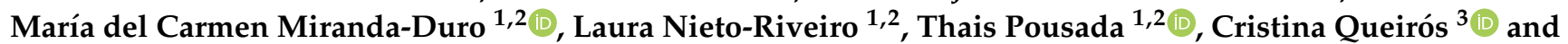 \\ Javier Pereira ${ }^{1,2} \mathbb{D}$
}

check for

updates

Citation: Concheiro-Moscoso, P.; Groba, B.; Martínez-Martínez, F.J.; Miranda-Duro, M.d.C.; Nieto-Riveiro, L.; Pousada, T.; Queirós, C.; Pereira, J. Study for the Design of a Protocol to Assess the Impact of Stress in the Quality of Life of Workers. Int. J. Environ. Res. Public Health 2021, 18, 1413. https://doi.org/10.3390/ ijerph18041413

Academic Editors: Jennifer L. Scheid and Paul B. Tchounwou

Received: 30 November 2020

Accepted: 30 January 2021

Published: 3 February 2021

Publisher's Note: MDPI stays neutral with regard to jurisdictional claims in published maps and institutional affiliations.

Copyright: (c) 2021 by the authors. Licensee MDPI, Basel, Switzerland. This article is an open access article distributed under the terms and conditions of the Creative Commons Attribution (CC BY) license (https:// creativecommons.org/licenses/by/ $4.0 /)$.
1 CITIC, TALIONIS Group, Elviña Campus, University of A Coruña, 15071 A Coruña, Spain; patricia.concheiro@udc.es (P.C.-M.); f.martinezm@udc.es (F.J.M.-M.); carmen.miranda@udc.es (M.d.C.M.-D.); laura.nieto@udc.es (L.N.-R.); thais.pousada.garcia@udc.es (T.P.); javier.pereira@udc.es (J.P.)

2 Faculty of Health Sciences, Oza Campus, University of A Coruña, 15071 A Coruña, Spain

3 Faculty of Psychology and Education Sciences, University of Porto, 4200-135 Porto, Portugal; cqueiros@fpce.up.pt

* Correspondence: b.groba@udc.es; Tel.: +34-881-015-870

\begin{abstract}
Background: Work stress is one of the most relevant issues in public health. It has a significant impact on health, especially the development of mental disorders, causing occupational imbalance. There is a growing interest in the development of tools with a positive effect on workers. To this end, wearable technology is becoming increasingly popular, as it measures biometric variables like heartbeat, activity, and sleep. This information may be used to assess the stress a person is suffering, which could allow the development of stress coping strategies, both at a professional and personal level. (2) Methods: This paper describes an observational, analytical, and longitudinal study which will be set at a research center in A Coruña, Spain. Various scales and questionnaires will be filled in by the participants throughout the study. For the statistical analysis, specific methods will be used to evaluate the association between numerical and categorical variables. (3) Discussion: This study will lay the foundation for a bigger, more complete study to assess occupational stress in different work environments. This will allow us to begin to understand how occupational stress influences daily life activity and occupational balance, which could directly enhance the quality of life of workers if the necessary measures are taken.
\end{abstract}

Keywords: work stress; occupational balance; occupational therapy; burnout; wearable technology; participatory health; Xiaomi Mi Smart Band 3

\section{Introduction}

Work is one of the most significant areas of occupation in adulthood, and has great relevance at a social and personal level throughout life [1,2]. Work and working conditions have a significant impact on health [3]. Stressful situations occur in the worker when these conditions are altered by different factors (work overload, lack of support, work schedules, or lack of family reconciliation) [4-6], giving rise to a specific type of stress called work stress $[7,8]$. Work stress is defined as "the reaction that the individual may have to work demands and pressures that do not match his knowledge and skills, and that test his ability to cope with the situation" [9].

It is estimated that work stress affects three million workers worldwide [10], and that it represents between $50-60 \%$ of the cases of absenteeism and presenteeism $[11,12]$. In addition, several studies have reported that the health sector suffers the most from this type of problem [13-15]. In line with this data, occupational stress has become one of the most relevant problems for public and occupational health [16-18].

Work-related stress has important repercussions at the personal and health levels, but also at the social level [19]. Several studies have reported that work-related stress is 
a trigger for mental disorders (specifically depression [14,20,21], sleep disorders [22,23], heart and/or respiratory diseases, and physical or cognitive fatigue [24,25]. Moreover, if work-related stress is prolonged and worsened over time, it can lead to burnout in the worker [26,27]. Burnout was defined by Maslach, Schaufeli, and Leiter as "a prolonged response to chronic emotional and interpersonal stressors at work, defined by the dimensions of exhaustion and inefficiency" [28].

In addition to the physical or psychological effects that work stress can have, it is also related to alterations in the occupational balance [29], defined as "a balance of engagement in occupation that leads to well-being. The balance may be among physical, mental, and social occupations; between chosen and obligatory occupations; between strenuous and restful occupations; or between doing and being" [30,31]. Several studies refer to the fact that workers experiencing occupational stress are not able to relativize work and everyday occupations, prioritizing paid employment and leaving aside activities related to social interactions, household management, and rest or sleep [29,32,33].

Some studies have associated alterations in occupational balance with perceived stress [17,32]. Both concepts include the demands, needs, and emotions associated with daily life activities, in order to obtain satisfaction and well-being [32]. Studies such as that by $\mathrm{Yu} \mathrm{Yu}$ et al. have emphasized the analysis of perceived stress [34,35], defined as "the individual's ability to cope with stressful situations" [36]. Its analysis can help us to understand different predictors of stress, and prevent alterations that lead to an occupational imbalance [17].

The effects derived from work stress suppose important direct and indirect consequences for public health $[16,37]$. They generate an expense to the system due to high demand on health services, and the necessity of treatments that must be maintained in the long term like antidepressants or anxiolytics, which have a minimum duration of several months $[38,39]$. In addition, there is an economic cost since factors associated with occupational stress, such as low self-esteem, dissatisfaction, and low efficiency in the labor field, affect short-term productivity [40,41]. In the long term, the consequences can be aggravated by the occurrence of workplace accidents or temporary or permanent disabilities, with these representing one of the main causes of early retirement [42-44].

Due to the aforementioned, various organizations associated with health and work have the objective of promoting quality of life and well-being, as well as greater productivity, in the worker $[11,45]$. They consider of interest the creation of strategies and technological solutions for the early detection and control of factors and effects associated with work stress, as well as balance between personal and work life and the promotion of healthy habits $[13,46]$.

Studies related to occupational stress have focused on the measurement of various physiological parameters for the detection of stress [47]. The most common biomarkers and indicators of stress are blood pressure and heart rate, which have been measured in these studies through the use of non-intrusive sensors to determine stress levels in workers $[48,49]$. However, these devices are generally uncomfortable for the user to carry for a long period of time, as is the case of belt-format pulsometers or portable electrocardiogram (EGC) devices $[47,50]$. Thus, it is necessary to find new sensors that are comfortable for the user, while providing information of equal quality [51].

In recent years, wearable devices for continuous, real-time monitoring of different parameters have been developed [52]. The measurement of parameters such as sleep and physical activity can be used to identify behavioral patterns of people when they are exposed to stressful situations [52]. Currently, the literature on the use of wearables for the measurement of occupational stress is focused on the development of automatic systems for the accurate assessment of stress, but less on the benefits of the study of stress at the social level [53-55]. However, studies such as that of Queirós et al. have already used Xiaomi wearable devices for public health purposes [56]. 
In this study, levels of work stress will be evaluated, along with how it influences the occupational balance and routine of workers. For this purpose, one of the most widely accepted wearables among the population will be used - the Xiaomi Mi Band 3-whose minute-by-minute measurements will be obtained through a data acquisition system developed by the research group. Likewise, specific scales and questionnaires will be used to measure the different aspects that influence quality of life.

\section{Objectives}

The main objective of this study is to assess the work stress level and its influence on the quality of life of workers at a research center.

The specific objectives are:

- To itemise the level of some parameters, such as activity, sleep, and heart rate.

- To determine the level and impact of occupational stress in worker's daily life through the information from wristbands and questionnaires.

- To identify patterns of occupational functioning, physical activity, and sleep in these people.

- To study the association between the identified patterns of occupational functioning, activity, and sleep, and the level of occupational stress and quality of life.

\section{Materials and Methods}

\subsection{Study Design}

This project will be a pilot study to determine the viability, sample size, cost, and duration of the study. Additionally, this project has been designed in order to "demonstrate that the planned measurements, the data collection instruments, and the data management system are feasible and effective" [57]. If this study proves to be successful, it will be performed with a larger sample from different work settings.

This study will be observational, analytical, and longitudinal. That is, in this study, different variables of the population under study will be observed and recorded without intervention, and with the aim of establishing causal associations between variables. It is considered longitudinal because the variables will be followed for six months, with continuous recording and monitoring of physical activity and the quality of sleep (wristbands). Variables related to work stress, quality of life, and perception of the quality of sleep and the level of physical activity (specific evaluation tools) will also be specifically measured [57]. This study protocol will follow the SPIRIT 2013 guidelines (See File S1) [58].

\subsection{Participants and Settings}

The study will be conducted in a research center in Galicia; a non-profit organization under private law whose aim is to contribute to the strengthening, empowerment, growth, and improvement of the competitiveness of the Galician information and communication technologies (ICT) sector. Sample selection will be performed through intentional sampling based on inclusion and exclusion criteria.

The participant inclusion criteria is: (a) performing management/administration/ research tasks at the research center.

The participant exclusion criteria is: (a) close to retirement (5 years or less); (b) significant health condition complications that prevented active participation in the study; and (c) hypersensitivity in the skin or a recognized allergy to the material of the cases or straps of the wearable wristbands used as one of the measuring instruments of the study. 


\subsection{Recruitment Process}

Entry into the study field will occur at the workplace where the project will be held. The participants will be recruited at the workplace, through an informative meeting that will be conducted at the facilities. In this meeting, the selection criteria for the study and the implications of participating will be presented, highlighting the total duration of participation and the mechanisms that will be followed at an ethical level to guarantee anonymity and the confidentiality of the data.

After the presentation of the main characteristics of the study to the workers attending the meeting, the information sheet will be given to any interested person to consider for as long as they wish, before making a decision regarding participation.

A week later, those workers willing to participate will be visited again to carry out the process of informed consent with the Principal Investigator (PI). In these individual meetings, possible doubts or queries will be resolved, the established selection criteria will be checked for each person, and the informed consent document will be signed if applicable.

\subsection{Justification of Sample Size}

This pilot study is being suggested in order to determine the feasibility, time, and cost required for a subsequent study, as well as to demonstrate that the selected measurements and instruments are feasible and effective, and to determine, based on the results, the optimal frequency, intensity, and duration of the study.

Likewise, by carrying out this pilot study, we will gain information about the standard deviation and the proportion of participants with the specific characteristics needed for this study, which will allow us to carry out the calculation of the sample size.

\subsection{Outcomes}

The primary outcome will be to determine the influence of stress and anxiety on the worker. The secondary measures will be: (a) sleep recording and physical activity tracking with the Xiaomi Mi Band 3; (b) quality of life self-perception with the EuroQol 5D-5L (EQ 5D-5L) scale; (c) determination of sleep habits by using the Pittsburgh Sleep Quality Index (PSQI); (d) anxiety self-perception by using the State-Trait Anxiety Inventory (STAI); (e) stress self-perception by using the Perceived Stress Scale-10 (PSS-10); and (f) influence of stress on daily functioning, by using a questionnaire designed by a work stress psychologist professional in consensus with the socio-sanitary professionals of the group.

\subsection{Data Collection and Management}

Prior to any other data, socio-demographic features of the participants considered as relevant will be collected using a record sheet of our own elaboration. This questionnaire includes questions regarding age, gender, marital status, residential environment, cohabitation unit, educational level, profession, socio-economic level, working hours, overtime working hours, level of perceived stress, other non-work-related stress factors, actions oriented to stress reduction, and medication intake.

Data will be collected from different sources (Figure 1). For biometrical data, a Xiaomi Mi Band 3 will be worn by all the participants for six months to measure their physical activity (steps), sleep (hours of sleep and sleep stages), and heart rate (bpm). A self-developed data collection system will be installed in one of the computers of the research center, capturing the data from the wristbands via Bluetooth every time they walk nearby and storing it in an Structured Query Language (SQL) database [59]. When the data is analyzed, it will be retrieved by the SQL database in which it was stored. The data will be exported through CSV in a detailed or accumulated way for analysis in any statistical program. 


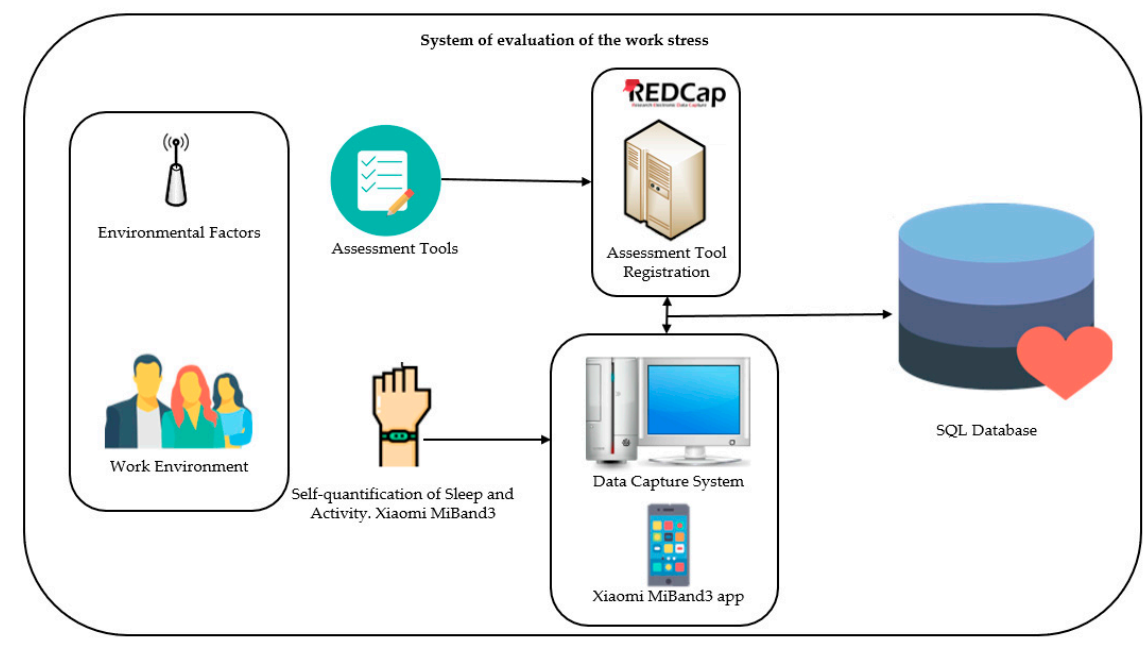

Figure 1. Registration and capture of biometric data and the assessment process.

The Research Electronic Data Capture Consortium (REDCap), a safe web application to create and manage online surveys and databases [60], will be used to digitally create the questionnaires and tests explained below, which will be sent to the participants to fill out.

In this study, participants will complete a set of assessment tools and a self-made questionnaire associated with work overload, sleep, and physical activity. These assessment tools will be filled in at the beginning and end of the study, while the self-made questionnaire will be answered throughout the study. This information is shown in Table 1.

Table 1. Measuring assessment tools.

\begin{tabular}{ccc}
\hline Instrument & Data & Delivery Phase \\
\hline EuroQol-5D-5L (EQ 5D-5L) & Quality of life & Beginning, follow-up, and completion \\
Pittsburgh Sleep Quality Index (PSQI) & Sleep habits & Beginning, follow-up, and completion \\
State-Trait Anxiety Inventory (STAI) & Anxiety & Beginning, follow-up, and completion \\
Perceived Stress Scale-10 (PSS-10) & Stress & Beginning, follow-up, and completion \\
Stress Questionnaire & Work stress factors and daily functioning & Daily (3 items) and weekly (4 items) \\
\hline
\end{tabular}

The scales to be completed are: (1) the EQ 5D-5L, which evaluates mobility, personal care, daily activities, pain/discomfort, anxiety/depression, and global status at the moment of assessment [61], (2) the PSQI, which analyzes the quantity, quality, duration, latency, and efficiency of sleep [62], (3) the STAI, which evaluates the presence of anxiety [63], and (4) the PSS-10, which measures the degree to which, during the last month, people have felt annoyed or worried or, on the contrary, have felt confident in their ability to control their personal problems [64].

Finally, a self-made questionnaire was developed considering the results of a prior poll that assessed different factors potentially related to stress. Those items that were directly related to stress were chosen for the questionnaire. This final questionnaire was agreed on by a stress psychologist professional. It is composed of three daily and four weekly items to answer (Appendix A), related to stress, work commitment and frustration, sleep, physical activity, and occupational balance. All items in the weekly and daily questionnaire are scored from 0 to $5(0=$ Nothing; 1 = Very little; 2 = Little; $3=$ Some; $4=$ Quite a lot; $5=$ A lot $)$.

\subsection{Data Analysis}

The statistical treatment of the data will be performed with the statistical package IBM SPSS Statistic version 22 (IBM, Chicago, IL, USA). The significance level for hypothesis testing is set at $5 \%$. The numerical variables will be expressed as the mean (M) and standard deviation (SD), including range, minimums, and maximums, while the categorical variables 
will be shown with their absolute frequency and valid percentage. In addition to the simple description of the data and variables studied, inferential analyses will be conducted in order to determine possible significant relationships between the variables of the study, or to allow the contrast of hypotheses. The Kolmogorov-Smirnov test will be applied to check that the variables behave as a normal distribution [65]. If not, non-parametric tests will be used in the subsequent analysis. The association of numerical variables will be analyzed with the Pearson or Spearman's Rho correlation test, depending on the distribution of the sample. To assess the association of categorical variables, the Chi-square test will be applied, or the likelihood ratio in the case that the frequencies observed are less than $5 \%$. In the case of the association between quantitative and qualitative variables, the comparison of means will be made with Student's $t$-test and analysis of variance (ANOVA) or Mann-Whitney and Kruskal-Wallis' U test, as appropriate [66]. Finally, and in order to determine whether there are significant and relevant differences between the results of the evaluations performed (initial, intermediate, and final), the Wilcoxon test will be applied [66]. Data analysis includes the cleaning or pre-processing, description, and processing of the stored data. The final objective of these steps is to obtain information for decision making. During pre-processing, erroneous data are removed or corrected to avoid bias in the results. Subsequently, a descriptive statistical study which summarizes certain relationships and distributions in a simple way will allow us to choose which processing strategy to adopt.

\subsection{Ethics and Dissemination}

This study protocol was approved by the A Coruña-Ferrol Research Ethics Committee under the number 2019/249, with the date of 24 April 2019. In addition, this protocol was registered in ClinicalTrials under the identifier NCT04584021, on 12 October 2020. It is available at https: / / clinicaltrials.gov/ct2/show /NCT04584021.

In case any change in the protocol is needed, this will be communicated to the Research Ethics Committee with the assigned reference number. These modifications will be updated in the Clinical Trials register.

The impact that the use of the procedures defined in the project may have on the protection of the personal data of the participants will be evaluated, emphasizing that such data will never leave the information system of the "Tecnología Aplicada a La Investigación en OcupacióN, Igualdad y Salud" (TALIONIS) Group, following the regulations of the Spanish and European Organic Law on the protection of personal data $[67,68]$. Data confidentiality and anonymity will be maintained through pseudonymization techniques. Once the study is completed, the data will be stored anonymously with the previous authorization of the participants.

The results of the questionnaires and assessment tools will be administered, coded, and managed through the software of REDCap. This platform complies with data protection regulations and stands out for being a widely used tool in clinical trials at an international level. The PI will have access to all the identification data of the participants and all the data collected during the study; the rest of the research team will have access to the data of the participants without identification through the REDCap platform, which allows the capture and consultation of the data anonymously.

The results related to the data of the wearable wristbands will be automatically captured through the wearable wristband data acquisition module. This platform was made following software design standards to guarantee the security and anonymization of the data during capture. It was developed in the Python programming language, along with the necessary libraries for the capture and storage of data in an anonymous way. The data is stored in an SQL server database that, together with the anonymization mechanisms and strategies created by the research team, has data masking mechanisms. In addition, it has limited access to data and security and access control mechanisms. Regarding Bluetooth technology, each bracelet has a unique internal key, generated at random, which is automatically changed. All these software resources are located in a 
small computer that will be placed in the environment of the center. This computer does not have input and output mechanisms to avoid any person outside the computer trying to access it. The PI will have access to the data related to the identification of the participants, and to the relationship of each participant with the internal number of each wristband. Once the study is finished, this data relationship will be eliminated.

\section{Discussion}

This pilot study may allow us to design a broader study with more participants in future. Stress is increasingly present in our society, and despite being historically understood as an expected effect derived from the mere activity of working, in recent years it has started to be considered as detrimental, but not unavoidable $[69,70]$. This kind of study could help with the control and detection of stress, influencing positively its reduction and improving the quality of life of workers [37]. In particular, if this study is successful, it would allow the evaluation of occupational stress by using cheap devices and easy-to-understand questionnaires that can be used by any person without any specific training. It would be possible to establish the influence that working stress has on the daily routines and occupational balance of workers.

In addition to the worldwide increase in stress, the emergence of coronavirus disease 2019 (COVID-19) has meant a significant worsening of the mental health of a large part of the population. Stress, along with anxiety and depression, have spread or become more severe during the pandemic in the general population [71]. Job instability due to unforeseeable lockdowns and restrictive measures leads to increased stress in the population, which along with precarious jobs, generates long-term uncertainty that can further increase general stress levels [72,73].

\section{Conclusions}

This project contributes to know the influence of occupational stress on the quality of life in a work environment. Therefore, it is intended to observe some parameters (activity, sleep, and heart rate) recorded through Xiaomi Mi Band 3. In addition, it aims to know about the level of work stress in diverse aspects of daily living, using various online self-report questionnaires in different periods of time. This data obtained from the questionnaires and wristbands will allow to determine the level of stress and its influences on quality of life during and after work.

The increasing use of portable devices such as smartphones or wearable devices encourages to obtain real-time biomedical data available for people, without going to health resources. Thus, this project considers as innovative that all measurements are registered online so that the workers can have an insight into their level of stress, the different stressful factors, and other parameters related to their activity, sleep, and heart rate, which influences their quality of life and work activity. It may help them to be more conscientious about their situation, so they can decide to make changes in their daily routines and habits.

Finally, considering the current pandemic situation, the online registration of all measurements will provide a follow-up of the participants without the need for face-toface meetings.

Supplementary Materials: The following are available online at https://www.mdpi.com/1660-4 601/18/4/1413/s1, File S1: Standard Protocol Items: Recommendations for Interventional Trials (SPIRIT).

Author Contributions: Conceptualization, J.P., C.Q. and B.G.; methodology, J.P, P.C.-M., M.d.C.M.-D., L.N.-R., T.P., and B.G.; investigation, J.P., P.C.-M., C.Q., and B.G.; writing-original draft preparation, F.J.M.-M., P.C.-M., and M.d.C.M.-D.; writing-review and editing, J.P., C.Q., B.G., L.N.-R., and T.P.; visualization, F.J.M.-M., P.C.-M., and M.d.C.M.-D.; supervision, J.P., B.G., C.Q., L.N.-R., and T.P.; project administration, J.P., B.G., L.N.-R., and T.P.; funding acquisition, P.C.-M., and M.d.C.M.-D. All authors have read and agreed to the published version of the manuscript. 
Funding: The authors disclose the receipt of the following financial support for the research, authorship, and/or publication of this article: All the economic costs involved in the study will be borne by the research team. This work is supported in part by some grants from the European Social Fund 2014-2020. CITIC (Research Centre of the Galician University System) and the Galician University System (SUG) obtained funds through the Regional Development Fund (ERDF) to cover $80 \%$ of the Operational Program ERDF Galicia 2014-2020, and the remaining 20\% was obtained by the Secretaría Xeral de Universidades of the Galician University System (SUG). Specifically, the author P.C.M. obtained a scholarship (Ref. ED481A-2019/069), and the author M.D.C.M.-D. (Ref. ED481A 2018/205) to develop the Ph.D. thesis. Furthermore, the diffusion and publication of this research are funded by the CITIC, as the Research Centre by Galician University System, with the support previously mentioned (Ref. ED431G 2019/01). In addition, this work is also supported in part by the Ministerio de Ciencia e Innovación $\mathrm{R}+\mathrm{D}+\mathrm{I}$ projects in the framework of the national programs of knowledge generation and scientific and technological strengthening of the R+D+I system, and challenges of society's oriented R+D+I 2019 call (PID2019-104323RB-C33).

Institutional Review Board Statement: This study was approved by the Research Ethics Committee of A Coruña-Ferrol (ref. 2019/249).

Informed Consent Statement: Informed consent was obtained from all participants involved in the study. Written informed consent has been obtained from the participants to publish this paper.

Data Availability Statement: Once the data collection process is finished and these have been coded, structured, and analyzed, these data will be provided, after the Spanish Data Protection Agency's consent, to any researcher that contacts TALIONIS group Principal Investigator, Javier Pereira (Javier.pereira@udc.es).

Acknowledgments: We would like to express our gratitude to the participants that have kindly agreed to be part of this study.

Conflicts of Interest: The authors declare no conflict of interest.

\section{Appendix A}

Table A1. Weekly and Daily Questionnaire Items.

\begin{tabular}{|c|c|}
\hline & Daily Questionnaire \\
\hline \multicolumn{2}{|r|}{$\begin{array}{l}\text { The three following questions, which reflect stress, work commitment, and frustration, will be } \\
\text { sent to participants on a daily basis. }\end{array}$} \\
\hline Item 1 & How exhausted did you feel today for reasons related to your work? \\
\hline Item2 & How motivated were you at work today? \\
\hline Item3 & How irritated or frustrated were you today for reasons related to your work? \\
\hline \multicolumn{2}{|r|}{ Weekly Questionnaire } \\
\hline \multicolumn{2}{|c|}{ The questions that will be sent on a weekly basis are the following: } \\
\hline \multirow{2}{*}{ Item 1} & $\begin{array}{l}\text { During this week you have been stressed out as a result of facing: } \\
+ \text { Meetings you consider pointless }\end{array}$ \\
\hline & * Communication problems \\
\hline Item 2 & During this week, have you felt that your sleep has been sufficient and repairing \\
\hline Item 3 & During this week, how do you evaluate the intensity of your physical activity? \\
\hline Item 4 & $\begin{array}{l}\text { During this week, how would you rate your occupational balance? Occupational balance is } \\
\text { understood as equal and optimal participation in your activities of daily life (work, } \\
\text { sleep and rest, self-care activities, home, and care activities, and leisure/free time). }\end{array}$ \\
\hline
\end{tabular}

\section{References}

1. American Occupational Therapy Association. Occupational Therapy Practice Framework: Domain E Process, 3rd ed.; American Occupational Therapy Association: Bethesda, MD, USA, 2014; Volume 68.

2. King, P.M.; Olson, D.L. Chapter 51: Work. In Willard \& Spackman: Occupational Therapy; Wolters Kluwer Health: Philadelphia, PA, USA, 2009; pp. 615-633.

3. Eisen, K.P.; Allen, G.J.; Bollash, M.; Pescatello, L.S. Stress management in the workplace: A comparison of a computer-based and an in-person stress-management intervention. Comput. Hum. Behav. 2008, 24, 486-496. [CrossRef] 
4. Okazaki, E.; Nishi, D.; Susukida, R.; Inoue, A.; Shimazu, A.; Tsutsumi, A. Association between working hours, work engagement, and work productivity in employees: A cross-sectional study of the Japanese Study of Health, Occupation, and Psychosocial Factors Relates Equity. J. Occup. Health 2019, 61, 182-188. [CrossRef] [PubMed]

5. Koura, U.; Sekine, M.; Yamada, M.; Tatsuse, T. Work, family, and personal characteristics explain occupational and gender differences in work-family conflict among Japanese civil servants. Public Health 2017, 153, 78-90. [CrossRef] [PubMed]

6. Huang, S.-L.; Li, R.-H.; Fang, S.-Y.; Tang, F.-C. Work Hours and Difficulty in Leaving Work on Time in Relation to Work-to-Family Conflict and Burnout Among Female Workers in Taiwan. Int. J. Environ. Res. Public Health 2020, 17, 605. [CrossRef]

7. Mostafa, A.M.S. High-Performance HR Practices, Work Stress and Quit Intentions in the Public Health Sector: Does personorganization fit matter? Public Manag. Rev. 2016, 18, 1218-1237. [CrossRef]

8. Blom, V.; Svedberg, P.; Bergström, G.; Mather, L.; Lindfors, P. Stress in paid and unpaid work as related to cortisol and subjective health complaints in women working in the public health care sector. Int. J. Work. Health Manag. 2017, 10, 286-299. [CrossRef]

9. Cox, T. Stress Research and Stress Management Putting Theory to Work; Health and Safety Executive Contract Research Report No. 61.; HSE Books: London, UK, 1993; ISBN 978-0717606849.

10. Beheshtifar, M.; Nazarian, R. Role of Occupational Stress in organizations. Interdiscip. J. Contemp. Res. Bus. $2013,4,648-657$.

11. Roy, M.; Simard, R.; Anaïs, F.; Généreux, M. Health promotion in the workplaces: Fostering resilience in times of organizational change. Can. J. Public Health 2019, 110, 792-800. [CrossRef]

12. Wushe, T.; Shenje, J. An analysis of the relationship between occupational stress and employee job performance in public health care institutions: A case study of public hospitals in Harare. SA J. Hum. Resour. Manag. 2019, 17, 11. [CrossRef]

13. Wu, S.Y.; Li, H.Y.; Tian, J.; Zhu, W.; Li, J.; Wang, X.R. Health-related quality of life and its main related factors among nurses in China. Ind. Health 2011, 49, 158-165. [CrossRef]

14. Wu, H.; Ge, C.X.; Sun, W.; Wang, J.N.; Wang, L. Depressive symptoms and occupational stress among Chinese female nurses: The mediating effects of social support and rational coping. Res. Nurs. Health 2011, 34, 401-407. [CrossRef] [PubMed]

15. Maharaj, S.; Lees, T.; Lal, S. Prevalence and Risk Factors of Depression, Anxiety, and Stress in a Cohort of Australian Nurses. Int. J. Environ. Res. Public Health 2018, 16, 61. [CrossRef] [PubMed]

16. Johnson, M.T.; Johnson, E. Stress, domination and basic income: Considering a citizens' entitlement response to a public health crisis. Soc. Theory Health 2019, 17, 253-271. [CrossRef]

17. Dèdelè, A.; Miškinytė, A.; Andrušaitytè, S.; Bartkutè, Ž. Perceived Stress Among Different Occupational Groups and the Interaction with Sedentary Behaviour. Int. J. Environ. Res. Public Health 2019, 16, 4595. [CrossRef] [PubMed]

18. Rigó, M.; Dragano, N.; Wahrendorf, M.; Siegrist, J.; Lunau, T. Work stress on rise? Comparative analysis of trends in work stressors using the European working conditions survey. Int. Arch. Occup. Environ. Health 2020, 15. [CrossRef] [PubMed]

19. Bhui, K.; Dinos, S.; Galant-Miecznikowska, M.; de Jongh, B.; Stansfeld, S. Perceptions of work stress causes and effective interventions in employees working in public, private and non-governmental organisations: A qualitative study. BJPsych Bull. 2016, 40, 318-325. [CrossRef]

20. Weston, G.; Zilanawala, A.; Webb, E.; Carvalho, L.A.; McMunn, A. Long work hours, weekend working and depressive symptoms in men and women: Findings from a UK population-based study. J. Epidemiol. Community Health 2019, 73, 465-474. [CrossRef]

21. Milner, A.; King, T. Men's work, women's work and suicide: A retrospective mortality study in Australia. Aust. N. Zeal. J. Public Health 2019, 43, 27-32. [CrossRef]

22. Kploanyi, E.E.; Dwomoh, D.; Dzodzomenyo, M. The effect of occupational stress on depression and insomnia: A cross-sectional study among employees in a Ghanaian telecommunication company. BMC Public Health 2020, 20, 1045. [CrossRef]

23. Cheng, P.; Drake, C. Shift Work Disorder. Neurol. Clin. 2019, 37, 563-577. [CrossRef]

24. Siegrist, J.; Li, J. Work Stress and the Development of Chronic Diseases. Int. J. Environ. Res. Public Health 2018, 15, 536. [CrossRef] [PubMed]

25. Niedhammer, I.; Sultan-Taïeb, H.; Chastang, J.F.; Vermeylen, G.; Parent-Thirion, A. Exposure to psychosocial work factors in 31 European countries. Occup. Med. 2012, 62, 196-202. [CrossRef] [PubMed]

26. Canu, I.G.; Mesot, O.; Györkös, C.; Mediouni, Z.; Mehlum, I.S.; Bugge, M.D. Burnout syndrome in Europe: Towards a harmonized approach in occupational health practice and research. Ind. Health 2019, 57, 745-752. [CrossRef] [PubMed]

27. Estévez-Mujica, C.P.; Quintane, E. E-mail communication patterns and job burnout. PLoS ONE 2018, 13, e0193966. [CrossRef] [PubMed]

28. Maslach, C.; Schaufeli, W.B.; Leiter, M.P. Job Burnout. Annu. Rev. Psychol. 2001, 52, 397-422. [CrossRef] [PubMed]

29. Håkansson, C.; Ahlborg, G. Occupational imbalance and the role of perceived stress in predicting stress-related disorders. Scand. J. Occup. Ther. 2018, 25, 278-287. [CrossRef] [PubMed]

30. Wilcock, A.A. Chapter 10. Occupation-Focused Approach to the Promotion of Health and Well-being. In An Occupational Perspective of Health, 2nd ed.; SLACK Incorporated: Thorofare, NJ, USA, 2006; pp. 305-335.

31. Wagman, P.; Håkansson, C.; Björklund, A. Occupational balance as used in occupational therapy: A concept analysis. Scand. J. Occup.Ther. 2012, 19, 322-327. [CrossRef]

32. Håkansson, C.; Ahlborg, G. Occupations, perceived stress, and stress-related disorders among women and men in the public sector in Sweden. Scand. J. Occup. Ther. 2017, 24, 10-17. [CrossRef]

33. Håkansson, C.; Ahlborg, G. Perceptions of employment, domestic work, and leisure as predictors of health among women and men. J. Occup. Sci. 2010, 17, 150-157. [CrossRef] 
34. Matuska, K.; Bass, J.; Schmitt, J.S. Life balance and perceived stress: Predictors and demographic profile. OTJR Occup. Particip. Health 2013, 33, 146-158. [CrossRef]

35. Yu, Y.; Manku, M.; Backman, C.L. Measuring occupational balance and its relationship to perceived stress and health. Can. J. Occup. Ther. 2018, 85, 117-127. [CrossRef] [PubMed]

36. Lazarus, R.; Folkman, S. Stress, Appraisal, and Coping; Springer Publishing Company: New York, NY, USA, 1984.

37. La Torre, G.; Sestili, C.; Mannocci, A.; Sinopoli, A.; De Paolis, M.; De Francesco, S.; Rapaccini, L.; Barone, M.; Iodice, V.; Lojodice, B.; et al. Association betweenwork related stress and health related quality of life: The impact of socio-demographic variables. A cross sectional study in a region of central Italy. Int. J. Environ. Res. Public Health 2018, 15, 159. [CrossRef] [PubMed]

38. Yang, B.; Wang, Y.; Cui, F.; Huang, T.; Sheng, P.; Shi, T.; Huang, C.; Lan, Y.; Huang, Y.-N. Association between insomnia and job stress: A meta-analysis. Sleep Breath. 2018, 22, 1221-1231. [CrossRef] [PubMed]

39. Lin, W.; Wang, H.; Gong, L.; Lai, G.; Zhao, X.; Ding, H.; Wang, Y. Work stress, family stress, and suicide ideation: A cross-sectional survey among working women in Shenzhen, China. J. Affect. Disord. 2020, 277, 747-754. [CrossRef] [PubMed]

40. Kerr, J.I.; Naegelin, M.; Weibel, R.P.; Ferrario, A.; La Marca, R.; von Wangenheim, F.; Hoelscher, C.; Schinazi, V.R. The effects of acute work stress and appraisal on psychobiological stress responses in a group office environment. Psychoneuroendocrinology 2020, 121, 104837. [CrossRef]

41. Verkuil, B.; Brosschot, J.F.; Gebhardt, W.A.; Korrelboom, K. Goal linking and everyday worries in clinical work stress: A daily diary study. Br. J. Clin. Psychol. 2015, 54, 378-390. [CrossRef]

42. Burr, H.; Pohrt, A.; Rugulies, R.; Holtermann, A.; Hasselhorn, H.M. Does age modify the association between physical work demands and deterioration of self-rated general health? Scand. J. Work. Environ. Health 2017, 43, 241-249. [CrossRef]

43. Navinés, R.; Martín-Santos, R.; Olivé, V.; Valdés, M. Workplace stress: Implications for physical and mental health. Clin. Med. 2016, 146, 359-366. [CrossRef]

44. Yang, T.; Liu, T.; Lei, R.; Deng, J.; Xu, G. Effect of Stress on the Work Ability of Aging American Workers: Mediating Effects of Health. Int. J. Environ. Res. Public Health 2019, 16, 2273. [CrossRef]

45. Leka, S.; Griffiths, A.; Cox, T. Work Organisation and Stress: Systematic Problem Approaches for Employers, Managers and Trade Union, 3rd ed.; World Health Organization: Geneva, Switzerland, 2003; ISBN 9241590475.

46. Ravalier, J.M.; Mcvicar, A.; Boichat, C. Work Stress in NHS Employees: A Mixed-Methods Study. Int. J. Environ. Res. Public Health. 2020, 17, 6464. [CrossRef]

47. Mozos, O.M.; Sandulescu, V.; Andrews, S.; Ellis, D.; Bellotto, N.; Dobrescu, R.; Ferrandez, J.M. Stress detection using wearable physiological and sociometric sensors. Int. J. Neural Syst. 2017, 27, 1650041. [CrossRef] [PubMed]

48. Koldijk, S.; Neerincx, M.A.; Kraaij, W. Detecting Work Stress in Offices by Combining Unobtrusive Sensors. IEEE Trans. Affect. Comput. 2018, 9, 227-239. [CrossRef]

49. Anusha, A.S.; Jose, J.; Preejith, S.P.; Jayaraj, J.; Mohanasankar, S. Physiological signal based work stress detection using unobtrusive sensors. Biomed. Phys. Eng. Express 2018, 4, 065001. [CrossRef]

50. Han, L.; Zhang, Q.; Chen, X.; Zhan, Q.; Yang, T.; Zhao, Z. Detecting work-related stress with a wearable device. Comput. Ind. 2017, 90, 42-49. [CrossRef]

51. El-Amrawy, F.; Nounou, M.I. Are Currently Available Wearable Devices for Activity Tracking and Heart Rate Monitoring Accurate, Precise, and Medically Beneficial? Healthc. Inform. Res. 2015, 21, 315-320. [CrossRef]

52. Peake, J.M.; Kerr, G.; Sullivan, J.P. A Critical Review of Consumer Wearables, Mobile Applications, and Equipment for Providing Biofeedback, Monitoring Stress, and Sleep in Physically Active Populations. Front. Physiol. 2018, 9, 743. [CrossRef]

53. Jacobs, J.V.; Hettinger, L.J.; Huang, Y.H.; Jeffries, S.; Lesch, M.F.; Simmons, L.A.; Verma, S.K.; Willetts, J.L. Employee acceptance of wearable technology in the workplace. Appl. Ergon. 2019, 78, 148-156. [CrossRef]

54. Elgendi, M.; Menon, C. Assessing anxiety disorders using wearable devices: Challenges and future directions. Brain Sci. 2019, 9, 50. [CrossRef]

55. Choi, B.; Hwang, S.; Lee, S.H. What drives construction workers' acceptance of wearable technologies in the workplace?: Indoor localization and wearable health devices for occupational safety and health. Autom. Constr. 2017, 84, 31-41. [CrossRef]

56. Queirós, C.; Oliveira, S.; Monteiro-Fonseca, S.; Marques, A.J. Stress at work and physiological indicators: A study with wearable sensors. Psicol. Saúde Doença 2020, 21, 183-190. [CrossRef]

57. Hulley, S.; Cummings, S.; Browner, W.; Grady, D.; Newman, T. Capítulo 9: Mejora de la inferencia causal en estudios de observación. In Diseño de Investigaciones Clínicas, 4th ed.; Wolters Kluwer Health: Barcelona, Spain, 2013 ; pp. $117-137$.

58. Chan, A.; Tetzlaff, J.M.; Altman, D.G.; Laupacis, A.; Gøtzsche, P.C.; Krleža-Jerić, K.; Hróbjartsson, A.; Mann, H.; Dickersin, K.; Berlin, J.A.; et al. SPIRIT 2013 Statement: Defining Standard Protocol Items for Clinical Trials. Ann. Intern. Med. 2013, 158, 200. [CrossRef]

59. Microsoft Microsoft Data Platform I Microsoft. Available online: https://www.microsoft.com/es-es/sql-server/ (accessed on 18 November 2020).

60. Vanderbilt University REDCap. Available online: https:/ /www.project-redcap.org/ (accessed on 18 November 2020).

61. Reenen, M.; van Janssen, B. EQ-5D-5L User Guide Basic. Information on How to Use the EQ-5D-5L Instrument; EuroQol Research Foundation: Rotterdam, The Netherlands, 2015.

62. Buysse, D.J.; Reynolds, C.F.; Monk, T.H.; Berman, S.R.; Kupfer, D.J. The Pittsburgh Sleep Quality Index (PSQI): A new instrument for psychiatric research and practice. Psychiatry Res. 1989, 28, 193-213. [CrossRef] 
63. Spielberger, C.D.; Gorsuch, R.L.; Lushene, R.; Vagg, P.R.; Jacobs, G.A. Manual for the State-Trait Anxiety Inventory; Consulting Psychologist Press: Palo Alto, CA, USA, 1970.

64. Lee, E.H. Review of the psychometric evidence of the perceived stress scale. Asian Nurs. Res. 2012, 6, 121-127. [CrossRef] [PubMed]

65. Conover, W.J. Several k-Sample Kolmogorov-Smirnov Tests. Ann. Math. Stat. 1965, 36, 1019-1026. [CrossRef]

66. Vargha, A.; Delaney, H.D. The Kruskal-Wallis Test and Stochastic Homogeneity. J. Educ. Behav. Stat. 1998, 23, 170-192. [CrossRef]

67. Agencia Española de Protección de Datos Reglamento General de Protección de Datos. Available online: http://www.agpd.es/ portalwebAGPD/temas/reglamento/index-ides-idphp.php (accessed on 25 November 2020).

68. The European Parliament and the Council of the European Union. Regulation (EU) 2016/679 of the European Parliament and of the Council of 27 April 2016 on the Protection of Natural Persons with Regard to the Processing of Personal Data and on the Free Movement of Such Data, and Repealing; The European Parliament and the Council of the European Union: Brussels, Belgium, 2016 ; pp. 45-62.

69. Casanova- Sotolongo, P.; Lima-Mompó, G.; Aldana-Vilas, L.; Casanova-Carrillo, P.; Casanova-Carrillo, C. El estrés ocupacional como una de las preocupaciones de la salud pública actual. Rev. Neurol. 2003, 36, 565. [CrossRef]

70. Ryu, S.; Kim, Y.W.; Kim, S.; Liao, Q.; Cowling, B.J.; Lee, C.-S. Occupational Stress among Field Epidemiologists in Field Epidemiology Training Programs from the Public Health Sector. Int. J. Environ. Res. Public Health 2019, 16, 3427. [CrossRef]

71. Shah, S.M.A.; Mohammad, D.; Qureshi, M.F.H.; Abbas, M.Z.; Aleem, S. Prevalence, Psychological Responses and Associated Correlates of Depression, Anxiety and Stress in a Global Population, During the Coronavirus Disease (COVID-19) Pandemic. Community Ment. Health J. 2021, 57, 101-110. [CrossRef]

72. Moretti, A.; Menna, F.; Aulicino, M.; Paoletta, M.; Liguori, S.; Iolascon, G. Characterization of Home Working Population during COVID-19 Emergency: A Cross-Sectional Analysis. Int. J. Environ. Res. Public Health 2020, 17, 6284. [CrossRef]

73. Sharma, N.; Vaish, H. Impact of COVID-19 on mental health and physical load on women professionals: An online cross-sectional survey. Health Care Women Int. 2020, 1-18. [CrossRef] 